\title{
A new class of laser dyes, 2-oxa-bicyclo[3.3.0]octa-4,8-diene-3,6-diones, with unity fluorescence yield $\dagger$
}

\author{
Chao-Yu Wang, Yu-Shan Yeh, Elise Y. Li, Yi-Hong Liu, Shiuh-Ming Peng, Shiuh-Tzung Liu* and \\ Pi-Tai Chou*
}

Received (in Cambridge, UK) 28th March 2006, Accepted 26th April 2006

First published as an Advance Article on the web 22nd May 2006

DOI: $10.1039 / \mathrm{b} 604539 \mathrm{a}$

A new class of highly fluorescent dyes, 4,8-diphenyl-2-oxabicyclo[3.3.0]octa-4,8-diene-3,6-diones (1a-c), have been synthesized, they all exhibit unity fluorescence quantum yield and short radiative lifetime $(<4 \mathrm{~ns})$ in common organic solvents and have demonstrated remarkable amplified spontaneous emission with a gain efficiency of $>10$.

Owing to their special photophysical properties such as high luminescent yield, subjective to environmental perturbation, etc., aromatic compounds possessing a six membered-ring lactone structure have been attracting much attention. ${ }^{1}$ Among these derivatives, $2 H$-chromen-2-one and its analogues have been ubiquitously applied as laser dyes, the categories of which have a well-known common name, "coumarin dyes". ${ }^{2}$ Applications other than laser dyes have also been explored in numerous territories such as ion and molecular recognition, ${ }^{3}$ two-photon absorption, ${ }^{4}$ etc. In comparison to six-membered-ring lactones, lactones with fused bicyclic five-membered rings are far less familiar. ${ }^{5}$ Particularly, to the best of our knowledge, there is no report on the corresponding optical applications up to the present time. In preparing polymers from the precursor 1-ethynylbenzene or its derivatives catalyzed by various $\mathrm{Rh}$ (or Ir) catalysts, ${ }^{5}$ we serendipitously explored a new series of 4,8-diphenyl-2-oxabicyclo[3.3.0]octa-4,8-diene-3,6-diones denoted as compounds 1a-c (see Scheme 1). In contrast to the generally recognized weak luminescent properties for five membered-ring lactones, 1a-c, with a small, simple molecular structure, all exhibit near unity, solvent

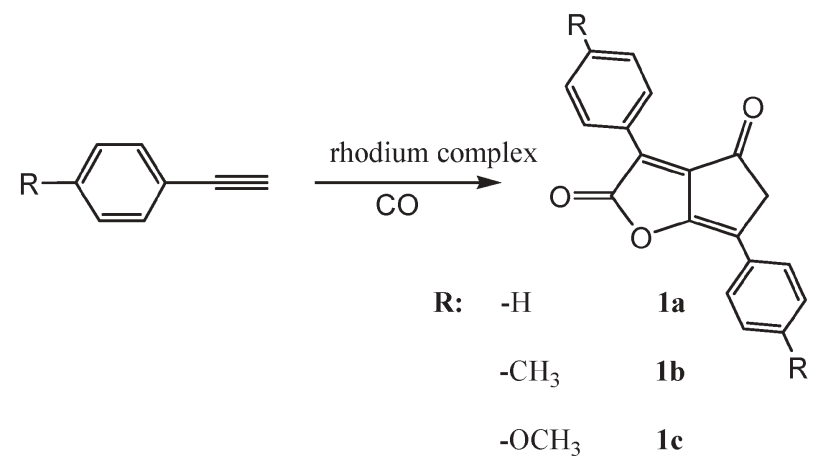

Scheme 1 The synthesis of compounds 1a-1c.

Department of Chemistry and Instrumentation Center, National Taiwan University, Taipei 106, Taiwan. E-mail: chop@ntu.edu.tw;

stliu@ntu.edu.tw; Fax: +886 (2) 2369 5208; Tel: +886 (2) 33663894

$\uparrow$ Electronic supplementary information (ESI) available: Detailed syntheses, characterization and measurements. See DOI: 10.1039/b604539a polarity independent visible fluorescence in common organic solvents. The emission peak wavelength can be tuned from green (526 nm, 1a) to orange-red ( $\sim 590 \mathrm{~nm}, 1 \mathbf{1 c})$. Detailed synthetic routes and unique photophysical properties such as the exploration of amplified spontaneous emission are elaborated below.

Compounds 1a-c were prepared according to a simple synthetic route, depicted in Scheme 1. ${ }^{6}$ As for a prototypical example for synthesizing 1a, an autoclave $(100 \mathrm{~mL})$ was loaded with phenylacetylene and rhodium complex (or other metal complexes) in dry toluene. The reactor was flushed with nitrogen several times and then pressurized with carbon monoxide. The reaction mixture was stirred at $110{ }^{\circ} \mathrm{C}$. After that, the solvents were evaporated and the residue was chromatographed on silica gel. The crude product was then recrystallized from diethyl ether to give $\mathbf{1 a}$ as a red-purple solid.

To optimize the yield of the desired product 1a, screening the reaction by using various rhodium complexes was performed, and the results are summarized in Table 1. The best activity for this transformation is the use of the rhodium carbonyl cluster $\left[\mathrm{Rh}_{6}(\mathrm{CO})_{16}\right](0.4 \mathrm{~mol} \%)$, giving rise to compound $1 \mathrm{a}$ as a red solid in $25 \%$ yield (entry 9). The products other than 1a were greasy materials, which were believed to be certain polymeric species.

In addition to the ${ }^{1} \mathrm{H}$ NMR and infrared spectroscopic data (see $\mathrm{ESI} \dagger)$, the ${ }^{13} \mathrm{C}$ NMR and single crystallographic measurement provide detailed structural information on 1a. ${ }^{13} \mathrm{C}$ NMR shifts at $\delta$ 191.3 (ketone) and 170.2 (ester) are characteristic of carbonyl carbons, which are consistent with the infrared $\mathrm{C}=\mathrm{O}$ stretching at 1752 and $1746 \mathrm{~cm}^{-1}$. Single crystals of $1 \mathrm{a}$ were obtained by recrystallization from chloroform.\$ X-Ray analyses revealed that there are two essentially identical molecules in the asymmetric unit of compound 1a. Thus, this system is statistically in between centrosymmetric and non-centrosymmetric space groups. The structure was solved under a non-centrosymmetric space group. Alternatively, we made an attempt to solve the structure by using a centrosymmetric space group but unfortunately failed. Fig. 1 shows an ORTEP plot of one of the two independent molecules of 1a. Selected bond distances, angles and dihedral angles are summarized in Table S1 (see ESI $\dagger$ ). All bond distances and bond angles of $\mathbf{1 a}$ are in the normal range. All $\mathrm{C}-\mathrm{C}$ single bonds except $\mathrm{C}(4)-\mathrm{C}(5)$ and $\mathrm{C}(5)-\mathrm{C}(6)$ are shorter than $1.54 \AA$, presumably due to the conjugation of $\pi$-bonds. A notable feature is the bond lengths of $\mathrm{C}(6)-\mathrm{C}(8)$ and $\mathrm{C}(2)-\mathrm{C}(14)$ (bonding between the phenyl ring and the bicyclic system), which might be due to the constraint arising from the fused bicyclic [3.3.0] system. The fused ring bicyclic system of 1a adopts a planar geometry, as evidenced by the dihedral angles $\mathrm{C}(6)-\mathrm{C}(7)-\mathrm{C}(3)-\mathrm{C}(2)\left[-179.5(6)^{\circ}\right]$ and $\mathrm{C}(4)-\mathrm{C}(3)$ $\mathrm{C}(7)-\mathrm{O}(1)\left[179.7(5)^{\circ}\right]$. Similar planarity was also resolved for the 
Table 1 Results of metal catalyzed coupling of phenylacetylene and $\mathrm{CO}^{a}$

\begin{tabular}{|c|c|c|c|c|c|}
\hline & Catalyst loading & Additive & $\mathrm{C}_{7} \mathrm{H}_{8} / \mathrm{ml}$ & Time/h & Yield $(\%)$ \\
\hline 1 & {$[\mathrm{Rh}(\mathrm{COD}) \mathrm{Cl}]_{2} 1.2 \mathrm{~mol}^{2} \%$} & - & 5 & 16 & 3 \\
\hline 2 & $\mathrm{RhCl}\left(\mathrm{PPh}_{3}\right)_{3} 10 \mathrm{~mol}^{\%} \%$ & - & 5 & 16 & Trace \\
\hline 3 & $\mathrm{RhCl}\left(\mathrm{PPh}_{3}\right)_{3} 10 \mathrm{~mol} \%$ & $\mathrm{AgBF}_{4} 10 \mathrm{~mol} \%$ & 5 & 16 & 0 \\
\hline 4 & {$[\mathrm{Rh}(\mathrm{COD}) \mathrm{Cl}]_{2} 1.2 \mathrm{~mol} \%$} & dppe $1.2 \mathrm{~mol} \%$ & 50 & 24 & 10 \\
\hline 5 & $\mathrm{Co}(\mathrm{OAc})_{2} 2.5 \mathrm{~mol} \%$ & - & 50 & 48 & 4 \\
\hline 6 & {$[\operatorname{Ir}(\mathrm{COD}) \mathrm{Cl}]_{2} 1.2 \mathrm{~mol} \%$} & - & 50 & 16 & 0 \\
\hline 7 & $\mathrm{Pd}(\mathrm{COD}) \mathrm{Cl}_{2} 2.5 \mathrm{~mol}^{\%}$ & - & 5 & 24 & 0 \\
\hline 8 & {$\left[\mathrm{RuCl}_{2}\left(\mathrm{C}_{10} \mathrm{H}_{14}\right)\right]_{2} 2.5 \mathrm{~mol} \%$} & - & 5 & 24 & 0 \\
\hline 9 & $\mathrm{Rh}_{6}(\mathrm{CO})_{16} 0.4 \mathrm{~mol}^{\circ} \%$ & - & 50 & 24 & 25 \\
\hline 10 & $\mathrm{Rh}_{6}(\mathrm{CO})_{16} 1.6 \mathrm{~mol} \%$ & - & 50 & 24 & 11 \\
\hline 11 & $\mathrm{Rh}_{6}(\mathrm{CO})_{16} 0.4 \mathrm{~mol}^{\%} \%$ & $2,2.5 \mathrm{~mol}^{1} \%$ & 50 & 24 & 18 \\
\hline
\end{tabular}

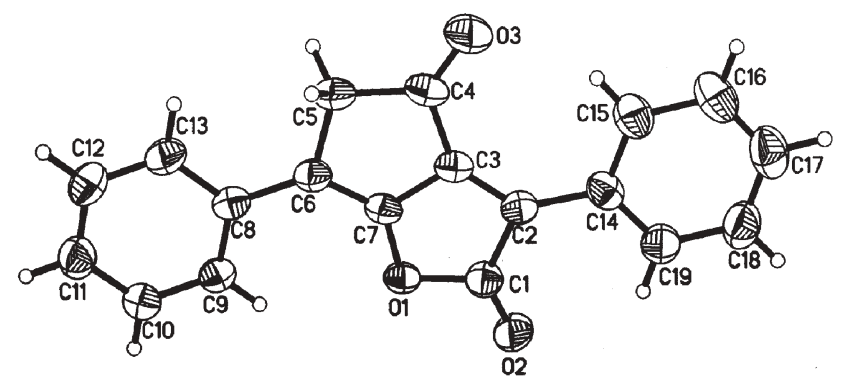

Fig. 1 A view of one of the two independent molecules of 1a, with ellipsoids drawn at the $30 \%$ probability level.

other independent molecule, as indicated by the dihedral angles $\mathrm{C}(25)-\mathrm{C}(26)-\mathrm{C}(22)-\mathrm{C}(21)\left[179.3(6)^{\circ}\right]$ and $\mathrm{C}(23)-\mathrm{C}(22)-\mathrm{C}(26)-\mathrm{O}(4)$ $\left[179.0(6)^{\circ}\right]$ (see Table S1 and Fig. S7 in ESI $\dagger$ ). The results clearly demonstrate conjugation via $\pi$ bonding. In addition, two phenyl rings are also coplanar with the bicyclic system, which is revealed by the dihedral angles of $\mathrm{C}(3)-\mathrm{C}(2)-\mathrm{C}(14)-\mathrm{C}(15)\left[-4(1)^{\circ}\right]$ and $\mathrm{C}(7)-\mathrm{C}(6)-\mathrm{C}(8)-\mathrm{C}(9)\left[2(1)^{\circ}\right]$. These observations indicate that this molecule is in a slightly distorted planar geometry.

Fig. 2 shows the room-temperature absorption and emission spectra of 1a-c in THF. Details of the photophysical properties of 1a-1c in THF are listed in Table 2. The observation of an $S_{0} \rightarrow S_{1}$ absorption band maximum at 446 (1a), 452 (1b) and $478 \mathrm{~nm}$ (1c) with an extinction coefficient as high as $\varepsilon=(2.5 \pm 0.5) \times 10^{4}$,

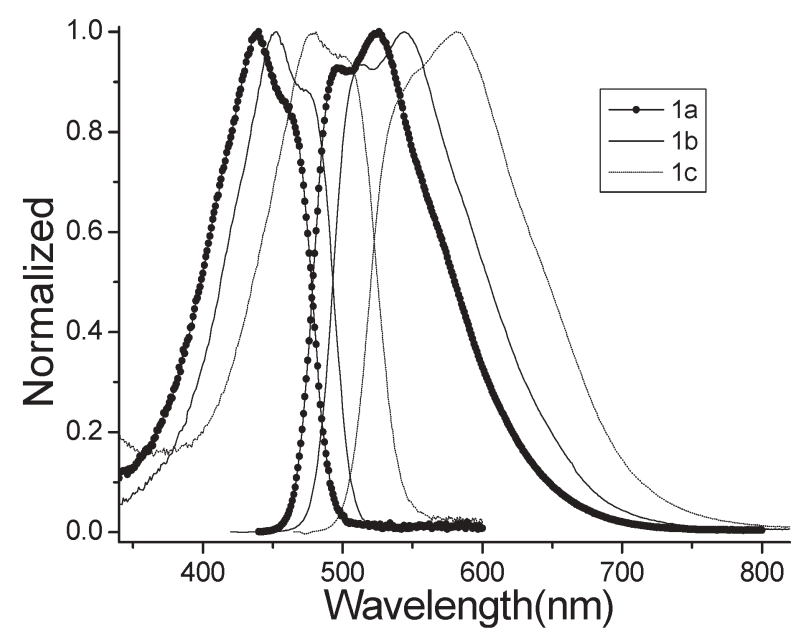

Fig. 2 Steady state absorption and fluorescence spectra for 1a-c in THF with an excitation wavelength of $\sim 400 \mathrm{~nm}$.
$(3.2 \pm 0.6) \times 10^{4}$ and $(2.8 \pm 0.6) \times 10^{4} \mathrm{M}^{-1} \mathrm{~cm}^{-1}$ for 1a, $\mathbf{1 b}$ and 1c, respectively, in THF suggests that the associated transition is an allowed $\pi \rightarrow \pi^{*}$ in character. The absorbance peak is linearly proportional to the added $\mathbf{1 a}-\mathbf{1 c}$ concentrations from $10^{-7}-10^{-4} \mathrm{M}$. This, in combination with the negligible change of the absorption profile, eliminates the possibility of an aggregation effect. 1a exhibits intensive emission with a peak wavelength at $526 \mathrm{~nm}$, which is nearly unperturbed by the solvent polarity. Rationally tuning of the transition gap, i.e. the peak wavelength, is achieved by the substitution of electron donating $-\mathrm{CH}_{3}$ (1) or $-\mathrm{OCH}_{3}$ (1c) groups on the phenyl group, giving an emission maximum at 544 and $586 \mathrm{~nm}$, respectively. The quantum yield, $\Phi_{\mathrm{f}}$, within experimental error, was measured to be $c a$. unity for all $1 \mathrm{a}-\mathbf{c}$ in both $\mathrm{CH}_{3} \mathrm{CN}$ and THF. The short radiative lifetime of $<4 \mathrm{~ns}$ for $\mathbf{1 a - c}$ further supports the predominantly radiative decay character.

Theoretical confirmation of the underlying basis for the photophysical properties of $\mathbf{1 a - 1 \mathbf { c }}$ was provided by the ab initio MO and time-dependent density function theory (TDDFT, see ESI $\dagger$ ) calculations. As for 1a, Table 3 depicts the descriptions and the $S_{0}-S_{1}$ energy gap as well as the features of the lowest unoccupied (LUMO) and highest occupied (HOMO) frontier orbitals, mainly involved in the $S_{0} \rightarrow S_{1}$ transition. Apparently, the electron densities of the HOMO are located largely on the delocalized $\pi$-orbital from the bicyclic core throughout the diphenyl moieties, while that of the LUMO are distributed mainly to the $\pi$-conjugated bicyclic core, indicating that the lowest electronic transition is dominated by a $\pi \pi^{*}$ character. According to the oscillator strength $f \sim 0.73$, the $S_{0} \rightarrow S_{1}$ transition from the $\mathrm{HOMO}$ is reasonably considered as an allowed process, for which the energy gap of $472 \mathrm{~nm}$ correlates well with the strong $\sim 450 \mathrm{~nm}$ absorption band with an extinction coefficient of $2.5 \times$ $10^{4} \mathrm{M}^{-1} \mathrm{~cm}^{-1}$ in THF. The addition of an electron donating $-\mathrm{CH}_{3}$ group on the phenyl ring should raise the HOMO energy, reducing the HOMO-LUMO gap. Further red-shifted emission in $\mathbf{1 c}$ is expected due to the stronger $-\mathrm{OCH}_{3}$ donating property from

Table 2 Photophysical properties of 1a-1c in THF (298 K)

\begin{tabular}{|c|c|c|c|c|c|c|}
\hline & $\mathrm{Abs} / \mathrm{nm}$ & $\lambda_{\mathrm{em}} / \mathrm{nm}$ & $\lambda_{\mathrm{ASE}}{ }^{a} / \mathrm{nm}$ & $\Phi_{\mathrm{f}}$ & $\tau_{\mathrm{f}} / \mathrm{ns}$ & Gain coefficient $^{b}$ \\
\hline 1a & 446 & 526 & 526 & 1.0 & 3.9 & 10.2 \\
\hline $1 b$ & 452 & 544 & 543 & 1.0 & 3.7 & 13.2 \\
\hline $1 \mathrm{c}$ & 478 & 586 & 563 & 1.0 & 3.5 & 10.8 \\
\hline
\end{tabular}


Table 3 The calculated energy level of the lowest-lying transition and the associated frontier orbitals for $\mathbf{1 a}$

\begin{tabular}{llll}
\hline \multicolumn{1}{c}{ Assignments } & $\lambda / \mathrm{nm}$ & $E / \mathrm{eV}$ & $F$ \\
\hline$S_{1} \quad \mathrm{HOMO} \rightarrow \operatorname{LUMO}(+72 \%)$ & 472 & 2.62 & 0.73 \\
$\mathrm{HOMO}$ & LUMO & &
\end{tabular}
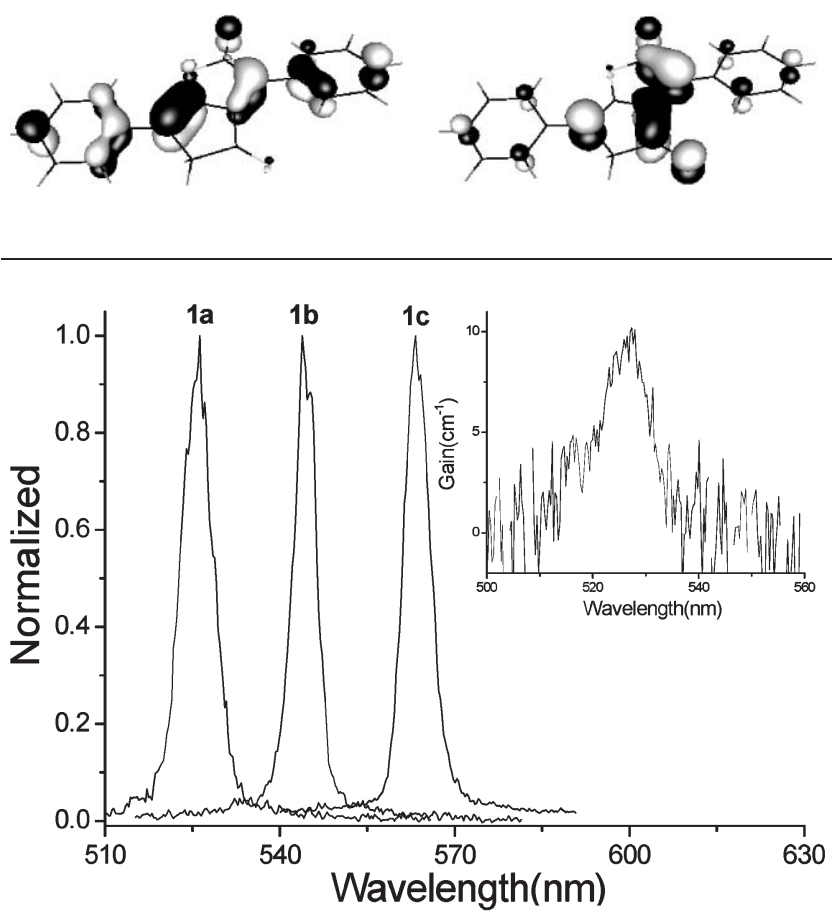

Fig. 3 Fluorescence and amplified spontaneous emission (ASE) of 1a $\left(2.1 \times 10^{-3} \mathrm{M}\right), \mathbf{1 b}\left(1.1 \times 10^{-3} \mathrm{M}\right)$ and $\mathbf{1 c}\left(2.3 \times 10^{-3} \mathrm{M}\right)$ in THF. Insert: ASE gain spectrum of $\mathbf{1 a}$ in THF at a pump power of $10 \mathrm{~mW}$. See text for the definition and experimental set up.

the HOMO, the predictions of which are consistent with experimental results.

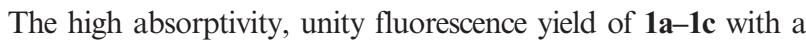
fast radiative decay time of $<4$ ns led us to examine the possibility of lasing properties through the measurement of amplified spontaneous emission (ASE) and its associated gain spectrum. In this experiment, optical gain measurements were carried out using the variable stripe length method. ${ }^{7}$ In this study, the second harmonic (443 nm, pulse width $8 \mathrm{~ns}$ ) of a Q-switched Nd:YAG pumped Ti:Sapphire laser was focused into a stripe on the quartz cell by a cylindrical lens. The stripe length was adjusted by a barrier coated with opaque material. The stripe was aligned near the edge of the square quartz cell, and the emission was collected from the edge at a $90^{\circ}$ angle with respect to the excitation beam. The emission was analyzed using a polychromator coupled to an intensified charge coupled detector.

Fig. 3 shows the ASE spectra of $\mathbf{1 a - 1 c}$ in THF. The exponential dependence of the intensity of the ASE on the gain coefficient $\alpha(\lambda)$ leads to the observed band narrowing. By measuring the intensity $I_{\mathrm{L}}$ of ASE from the entire cell length $L$ and the intensity $I_{L / 2}$ from the cell half-length, one can evaluate the ASE gain $\alpha(\lambda){ }^{8}$ expressed as

$$
\alpha(\lambda)=\frac{2}{L} \ln \left[\frac{I_{L}}{I_{L / 2}}-1\right]
$$

The wavelength dependence of the ASE gain coefficient, i.e. the gain spectrum, is obtained from the analysis of the spectroscopic data recorded using the above equation. As shown in the insert of Fig. 3, the experimental gain spectrum of $\mathbf{1 a}$ in THF at a pump power of $10 \mathrm{~mW}$ covered a region from $\sim 500$ to $560 \mathrm{~nm}$ with a maximum at $526 \mathrm{~nm}$ and a gain efficiency of $\sim 10$, which is comparable with many other commercially available laser dyes. The lack of a triplet state $\left(\mathrm{T}_{1}\right)$ population, and hence no interference from the $\mathrm{T}_{1}-\mathrm{T}_{n}(n>1)$ absorption at the ASE region, is believed to play a key factor for observing the stimulating emission. Similar results were obtained for $\mathbf{1 b}$ and $\mathbf{1 c}$, with ASE peak wavelengths 543 and $563 \mathrm{~nm}$, respectively (see Table 2). In the case of $\mathbf{1 b}$, a maximum gain efficiency of as high as 13.2 can be obtained. As for a test of stability, for $\mathbf{1 a - c}$, the ASE remained unchanged with $10 \mathrm{~mW}(443 \mathrm{~nm}, 10 \mathrm{~Hz})$ pumping within a period of one hour. This, in combination with the tunability of ASE, generates a new series of potential laser dyes in the green-orange region.

In conclusion, we have synthesized a new class of highly fluorescent dyes, $\mathbf{1 a - c}$, that all exhibit unity fluorescence quantum yield and short radiative lifetime $(<4 \mathrm{~ns})$ in common organic solvents. The $\pi \pi^{*}$ transition character has been fully justified via theoretical approaches. 1a-c also demonstrate remarkable amplified spontaneous emission with a gain efficiency of $>10$. This, in combination with the excellent photostability, makes 1a-c potentially novel laser dyes incorporating a bicyclic, fused five membered-ring lactone structure. Future applications of this series of dyes are wide ranging. For example, through a strategic design of the substituents on the phenyl group, syntheses of water-soluble fluorescent dyes can be achieved, such that their applications toward fluorescent imaging and biomolecular recognition become feasible. Work focusing on this issue is currently in progress.

\section{Notes and references}

† Crystal data for 1a: $\mathrm{C}_{19} \mathrm{H}_{12} \mathrm{O}_{3}(M=288.29)$, orthorhombic, space group Pca2 $_{1}, a=11.7937(4), b=12.9224(5), c=18.4121(6) \AA ⿻, \alpha=\beta=\gamma=90^{\circ}$, $V=2806.1(2) \AA^{3}, Z=8, \mu=0.092 \mathrm{~mm}^{-1}, D_{\mathrm{c}}=1.365 \mathrm{~g} \mathrm{~cm}^{-3}, T=295(2)$ $\mathrm{K}, 2533$ independent reflections $\left(R_{\mathrm{int}}=0.1298\right)$, final $R$ indices (398 parameters) $[I>2 \sigma(I)]$ are $R 1=0.0692, w R 2=0.1411$, $\mathrm{GOF}=1.039$. CCDC 602233. For crystallographic data in CIF or other electronic format see DOI: 10.1039/b604539a

1 (a) R. Touzani and H. Alper, J. Mol. Catal. A: Chem., 2005, 227, 197; (b) C. Dong and H. Alper, J. Org. Chem., 2004, 69, 5011; (c) G. Vasapollo, G. Mele and B. E. Ali, J. Mol. Catal. A: Chem., 2003, 204-205, 97.

2 (a) E. Aktoudianakis and A. P. Dicks, J. Chem. Educ., 2006, 83, 287; (b) R. B. Bangar and T. S. Varadarajan, Appl. Phys. B, 1997, 59, 83.

3 (a) S. Sen, N. A. Paraggio, L. A. Gearheart, E. E. Connor, A. Issa, R. S. Coleman, D. M. Wilson, 3rd, M. D. Wyatt and M. A. Berg, Biophys. J., 2005, 89, 4129; (b) H. Shirota, H. Pal, K. Tominaga and K. Yoshihara, J. Phys. Chem. A, 1998, 102, 3089.

4 W. G. Fisher, E. A. Wachter, F. E. Lytle, M. Armas and C. Seaton, Appl. Spectrosc., 1998, 52, 536.

5 J. Kiji, S. Yoshikawa and J. Furukawa, Bull. Chem. Soc. Jpn., 1974, 47, 490.

6 C.-Y. Liu, D.-Y. Chen, G.-H. Lee, S.-M. Peng and S.-T. Liu, Organometallics, 1996, 15, 1055.

7 K. L. Shaklee, R. E. Nahory and R. F. Leheny, J. Lumin., 1973, 7, 284.

8 (a) W. T. Silfvast and J. S. Deech, Appl. Phys. Lett., 1967, 17, 97; (b) O. G. Peterson, J. P. Webb, W. C. McColgin and J. H. Eberly, J. Appl. Phys., 1971, 42, 1917; (c) C. V. Shank, Rev. Mod. Phys., 1975, 47, 649. 